\title{
Geologic Evaluation of Kirkuk Underground Storage Project
}

\section{Al-Sulaiman FA*, Fadaws AH" $^{*}$ and Ahmed TA}

Petroleum Engineering Department, North Oil Company, Qatar

${ }^{\text {"Equally Contributed }}$

\begin{abstract}
Geologic evaluation of the Kirkuk underground was conducted by comparison of the geometric properties of the cavities derived from two surveys running during 1989 and 2015. The vertical cross sections of the cavities show that most cavities have shown that most cavities have irregular shape because of the presence of impurities in the salt bed that cause different leaching velocities in different directions. The relationship of the cavity roof with tilted salt bed was studied, that shows some of the cavities are not safe to store LPG.
\end{abstract}

Keywords: Underground storage; Salt cavern; Salt mine solution; Salt leaching

\section{Introduction}

Storage of liquids and gases in solution mined salt caverns was reportedly first in Canada in the early 1940s during world war. Storage in the salt caverns of liquid petroleum gas (LPG) and other light hydrocarbons spread rapidly in the early 1950s in North America and several European countries. Storage of crude oil reportedly occurred first in England, also in 1950s during the Suez crisis. Natural Gas Storage followed the storage of liquid hydrocarbons by about decade in the USA and Canada [1]. Kirkuk underground storage project locate on the southern west limb of Kirkuk anticline near Kirkuk city, North Iraq (Figure 1). In 1978 eight wells were drilled for the purpose of LPG storage, five wells of them $(2,5,6,7,8)$ were selected for leaching operations as the thickness of salt layer in these wells was suitable to create cavern of salt and economical size.

\section{Salts deposits in Iraq}

The evaporate deposits exposed on the surface, as well as penetrated by oil and gas wells in different areas and ages in Iraq, these exposures and penetrated wells sections were different in their extensions, types

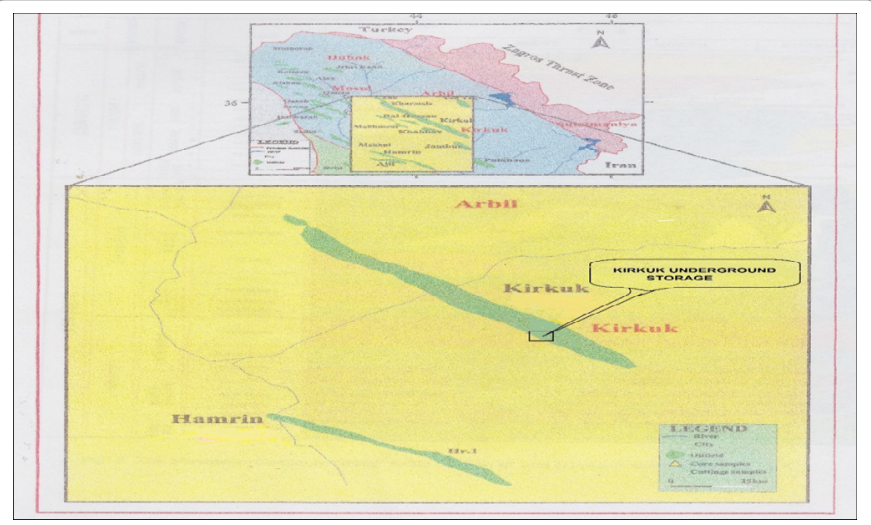

Figure 1: Location map for study area.

\begin{tabular}{|c|c|c|}
\hline Well no. & Thickness of upper Salt bed $(\mathbf{m})$ & Thickness of lower salt bed $(\mathbf{m})$ \\
\hline KGS-2 & 8 & 73 \\
\hline KGS-5 & 22 & 68.6 \\
\hline KGS-6 & 22.8 & 60 \\
\hline KGS-7 & 16 & 79 \\
\hline KGS-8 & 31.3 & 81.2 \\
\hline
\end{tabular}

Table 1: Thickness of upper and lower salt bed in the study area. and their depths, this rock salt deposits are recorded in subsurface sections within Middle Miocene Fatha formation and lower Miocene Dhiban formation [2]. They were deposited in the central parts of large evaporitic basins in association of gypsum. The total thickness of the salt beds ranges from (80-65) m, [3]. The upper Jurassic Gotnia anhydrite formation was laid down in super saline lagoon and represents the oldest one among numerous Upper Jurassic saline basins [2].

Fatha formation (previously referred as lower fars) and its equivalent in Iran and Syria, represent the most important formations that contain thick salt bed. Fatha formation was settled in Middle Miocene in shallow marine basin extending (North west-south east) orientation from Mosul to the south-western boundary of iran via Kirkuk. Fatha formation consist of four geological series, Transition beds, Saliferous beds, Seepage beds and upper red beds from the oldest to the youngest. Saliferous beds including approximately five evaporitic cycles of halite deposits, without reaching the potassium chloride (KCL) deposits. Among the halite deposits, two main halite deposits can be identified which were referred to be upper thick salt bed and lower thick salt (Table 1) (final well report of KGS-2, 5, 6, 7, 8) [4]. The thickness variation of the salt beds is related to the creeping and flowage of the salts due to the horizontal stresses derived from continental collision between Arabian and Iranian plates that causes the thrusting of north east limb of Kirkuk anticline on the south west limb [5].

\section{Leaching Operations and Sonic Surveys}

During April/1982-Feb/1984 leaching operations were carried out on these wells as mathematical model proposed for leaching [6]. During the $3^{\text {rd }}$ step of leaching in cavity (KGS-7) differences appeared between theoretical calculations by using the mathematical model and the field results depending on water injection rate and the brine salinity, which caused occurrence of ears in the wall of cavity, that was obviously noticed in sonic survey. This phenomenon caused by impurities in salt that having higher leaching velocity than salt, or by random leaching

"Corresponding author: Al-Sulaiman FA, Petroleum Engineering Department, North Oil Company, Qatar, Tel: 009647701250679 ; E-mail: drfaraj_sulaiman@yahoo.com

Received August 02, 2017; Accepted August 26, 2017; Published August 31, 2017

Citation: Al-Sulaiman FA, Fadaws AH, Ahmed TA (2017) Geologic Evaluation of Kirkuk Underground Storage Project. J Pet Environ Biotechnol 8: 340. doi: 10.4172/2157-7463.1000340

Copyright: @ 2017 Al-Sulaiman FA, et al. This is an open-access article distributed under the terms of the Creative Commons Attribution License, which permits unrestricted use, distribution, and reproduction in any medium, provided the original author and source are credited. 
operations. About eight sonic survey were conducted in (KGS-2, 5, 6, 7,8 ) during the period 1982-1984 to assess leaching operation, with additional survey to some of the cavities during 1984 and 1989.

All recorded echo time were converted into distances supposing rectilinear propagation of sonic waves by utilizing a constant velocity of $(1750 \mathrm{~m} / \mathrm{s}, 1742 \mathrm{~m} / \mathrm{s}, 1790 \mathrm{~m} / \mathrm{s}, 1765 \mathrm{~m} / \mathrm{s}$ and $1761 \mathrm{~m} / \mathrm{s}$ for the cavities (KGS-2, 5, 6, 7, 8 respectively) [4]. In addition to the converted times of the horizontal panoramic echograms were prepared as horizontal cross sections. A further twelve vertical cross sections (0-360) were constructed.

The last sonic survey was conducted during April /2015 and the outputs of this survey were horizontal cross section every meter from the top to the bottom of the cavity, as well as vertical cross sections every $5^{\circ}$ from $\left(0^{\circ}-360^{\circ}\right)$. The vertical cross sections have $1 \mathrm{~cm}: 5 \mathrm{~m}$ vertical scale and $1 \mathrm{~cm}: 5 \mathrm{~m}$ horizontal scale.

For the purpose of comparison of the results of the 1989 survey

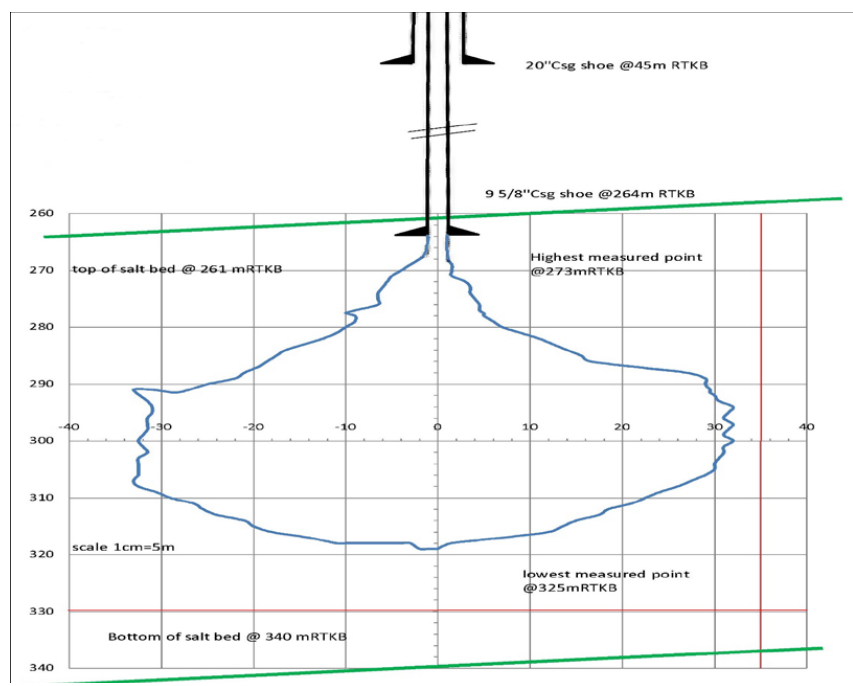

Figure 2: Converted vertical cross sections prepared from the sonic survey conducted during 1989 by using excel program.

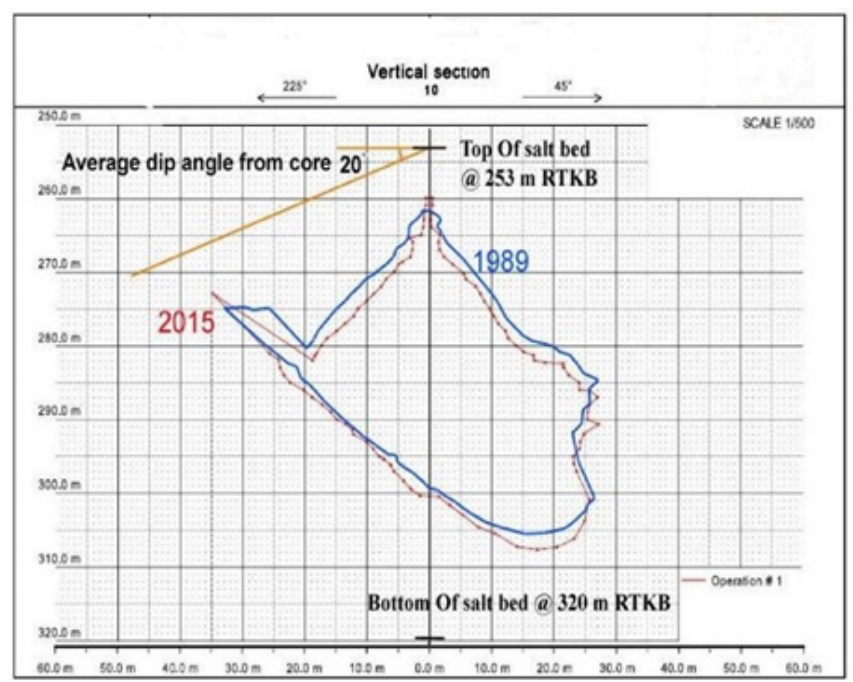

Figure 3: The super-imposition of vertical cross section for 1989 and 2015 survey of cavity no 2 .

\begin{tabular}{|c|c|c|c|c|}
\hline Date & $\begin{array}{c}\text { Highest } \\
\text { point (mRTKB) }\end{array}$ & $\begin{array}{c}\text { Lowest } \\
\text { point (mRTKB) }\end{array}$ & $\begin{array}{c}\text { Total depth } \\
(\mathbf{m R T K B})^{*}\end{array}$ & Volume $\mathbf{( m}^{3}$ ) \\
\hline 1989 & 262 & 306 & 299 & 40660 \\
\hline 2015 & 260 & 307 & 300 & 39807 \\
\hline RTKB: Rotary Table Kelly Bushing. & & \\
\hline
\end{tabular}

Table 2: Geometric properties of the cavity no 2.

with last sonic survey conducted during 2015, the vertical cross sections prepared from the sonic survey conducted during 1989 that have different scale, using excel program was converted, to sections have the same scale of the sections resulted from the last sonic survey for example (Figure 2).

\section{Results and Discussion}

The geologic evaluation of the gas storage project is controlled by the thickness of salt bed, impurities in the salts, attitude of the salt bed (dip and dip direction of the salt bed) and tectonic setting of the area. The thickness of the salt bed in the area of the project show highly variation from location to location $(25-81) \mathrm{m}$ this thickness variation is due to tectonic activity that caused thrusting of north east limb along the saliferous bed of Fatha formation as detachment surface and squeezing salt bed to south west limb of Kirkuk anticline. To evaluate Kirkuk underground storage project we will assess every cavity individually.

\section{Cavity no. 2}

The superimposition of the vertical cross section of 1989 survey on the vertical cross section of the year 2015 survey with plotting the top of salt bed that dips $20^{\circ}$ to SW (Figure 3) show that the deformation(breakdown) of cavity wall was in the SW direction, in the two surveys. The core descriptions of this cavity refer to presence of marl and silt as inclusions in the salt bed that cause such deformation and irregular surface of the cavity wall. The geometric properties of the cavity derived from 1989 and 2015 survey show variations between two surveys (Table 2).

These variations are may related to the instrument accuracy, we believe that the accuracy of instrument used in 2015 is more than that used in 1989, due to the huge developments of electronics devices and software for interpretations during last 25 years, in addition to the sonar that used in 2015 survey measures the horizontal and vertical section every $5^{\circ}$ rotation and tilt angle and every $1 \mathrm{~m}$ through the whole depth of the cavity unfortunately, the direction of breakdown is to SW, that represent the direction where the cavity roof be the nearest to top of the salt bed (Figure 3). The cavity can be used for LPG storage after conducting tightness test.

\section{Cavity no. 5}

The vertical cross sections of the survey conducted during the years of 1989 and 2015 and it is relationship with the attitude of salt bed (Figure 4) shows the irregular surface of cavity wall due to the presence of marls as inclusions in the salt bed up to $4 \%$ (core descriptions) that cause difference in leaching velocities in different direction. In addition to the maximum extension of the cavity about $57 \mathrm{~m}$ in $\left(219^{\circ}-39^{\circ}\right)$ direction at the depth $313 \mathrm{Mrtkb}$.

The geometric properties of cavity according to the two surveys (Table 3) show some variations in it is extensions in different directions and reduction in the size of the cavity by about $1367 \mathrm{~m}^{3}$. This reduction attribute to the high accuracy of the instrument used in the last survey that conduced during 2015, and because of the flowage of salt especially the cavity was empty during the last ten years ago and wall of cavity was not supported by suitable pressure. The vertical cross section Figure 4 
Citation: Al-Sulaiman FA, Fadaws AH, Ahmed TA (2017) Geologic Evaluation of Kirkuk Underground Storage Project. J Pet Environ Biotechnol 8: 340. doi: $10.4172 / 2157-7463.1000340$

Page 3 of 4

shows that the roof of the cavity is very near to of the salt bed (about 2 $\mathrm{m})$, this made the cavity not safe to store the LPG.

\section{Cavity no. 6}

The vertical cross sections for the two surveys conducted during the years of 1989. Figure 5 shows that the shape of the cavity is conical with irregular floor surface, and this was expected due to presence of marls and the core description refer to that the salt was transparent to translucent. The plotting of the top salt bed with dip angle $\left(10^{\circ} / 45^{\circ}\right)$ refer clearly that the roof of cavity is far enough, that made the cavity is suitable to store the LPG (Figure 5).

The comparison of the geometric properties of cavity for the two surveys (Table 4) show variation and high increase of the cavity volume

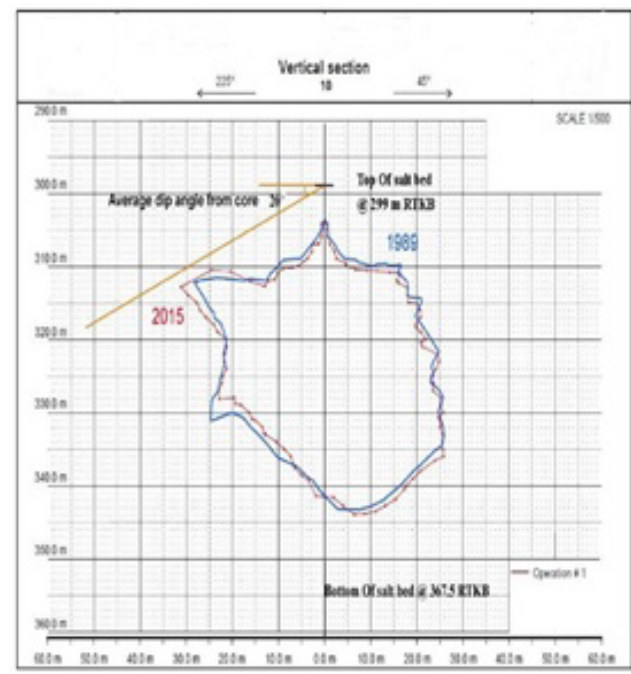

Figure 4: The super-imposition of vertical cross section for 1989 and 2015 survey of cavity no 5 .

\begin{tabular}{|l|c|c|c|c|}
\hline Date & $\begin{array}{c}\text { Highest } \\
\text { point (mRTKB) }\end{array}$ & $\begin{array}{c}\text { Lowest } \\
\text { point( } \mathbf{m R T K B})^{*}\end{array}$ & $\begin{array}{c}\text { Total depth } \\
\text { (mRTKB) }\end{array}$ & Volume $\mathbf{( m}^{\mathbf{3}}$ ) \\
\hline 1989 & 304 & 343.4 & 341.2 & 42790 \\
\hline 2015 & 304 & 343.8 & 341.5 & 41423 \\
\hline
\end{tabular}

Table 3: Geometric properties of the cavity no 5.

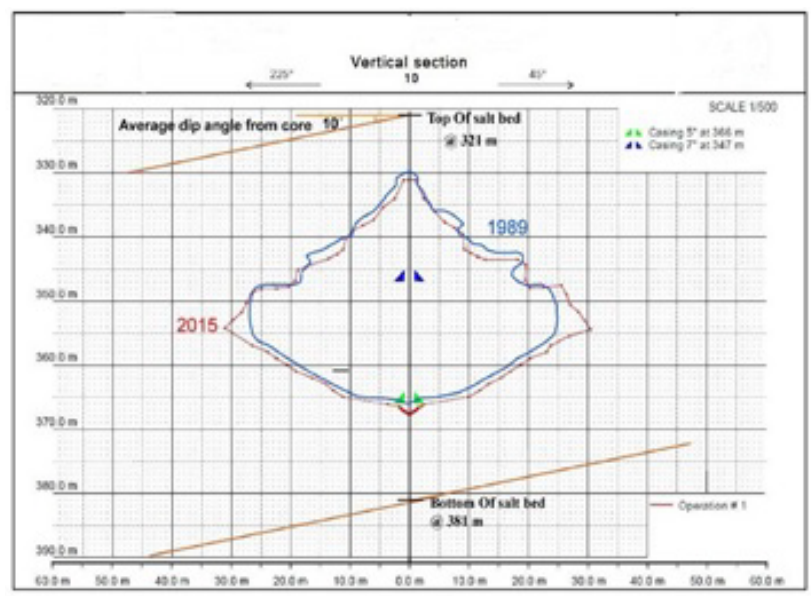

Figure 5: The super-imposition of vertical cross section for 1989 and 2015 survey of cavity no 6 .

\begin{tabular}{|c|c|c|c|c|}
\hline Date & $\begin{array}{c}\text { Highest } \\
\text { point (mRTKB) }\end{array}$ & $\begin{array}{c}\text { Lowest } \\
\text { point (mRTKB) }\end{array}$ & $\begin{array}{l}\text { Total depth } \\
\text { (mRTKB) }\end{array}$ & Volume $\left(\mathrm{m}^{3}\right)$ \\
\hline 1989 & 330 & 365.9 & 365 & 30760 \\
\hline 2015 & 331 & 368 & 368 & 37676 \\
\hline
\end{tabular}

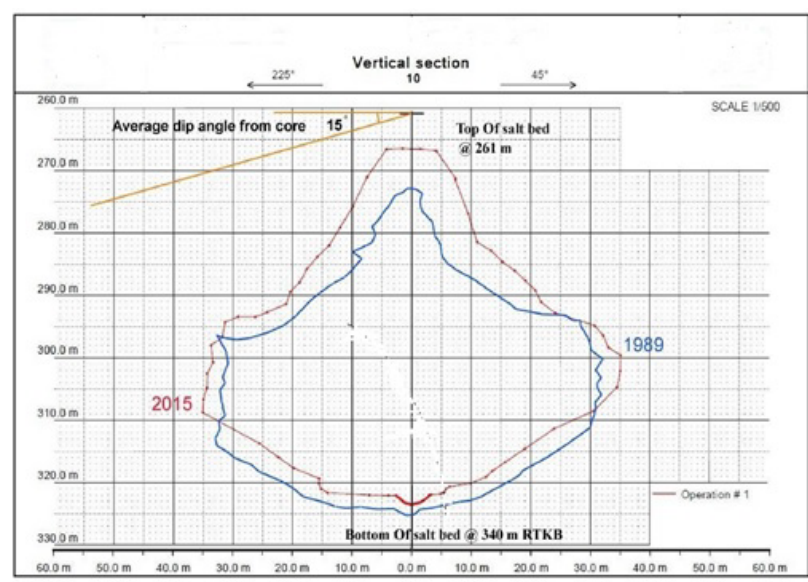

Figure 6: The super-imposition of vertical cross section for 1989 and 2015 survey of cavity no 7 .

\begin{tabular}{|c|c|c|c|c|}
\hline Date & $\begin{array}{c}\text { Highest } \\
\text { point (mRTKB) }\end{array}$ & $\begin{array}{c}\text { Lowest } \\
\text { point (mRTKB) }\end{array}$ & $\begin{array}{c}\text { Total depth } \\
\text { (mRTKB) }\end{array}$ & Volume (m $\mathbf{m}^{3}$ ) \\
\hline 1989 & 273 & 325 & 325 & 76730 \\
\hline 2015 & 266.5 & 323.5 & 323.5 & 86542 \\
\hline
\end{tabular}

Table 5: Geometric properties of the cavity no.7

\begin{tabular}{|c|c|c|c|c|}
\hline Month & August & September & October & November \\
\hline Injection Operation & 5 & 11 & 12 & ------ \\
\hline Withdraw Operation & ------ & ------ & ------ & 2 \\
\hline
\end{tabular}

Table 6: Operation activities (injection and withdraw) for cavity no 7 during 2013.

up to $\left(6916 \mathrm{~m}^{3}\right)$, this high-volume increase is due to bad operations conditions that related to pumping under saturated brine while unloading the cavity, that case homogenous leaching during that last 25 years.

\section{Cavity no. 7}

The vertical cross sections for the two surveys conducted during the years of 1989 and 2015 show regular conical shape of the cavity (Figure 6). The core description of the salts refers to that the salt was pure, crystalline, transparent, and white, these properties give the regular shape of the cavity. Dip measurement taken from the care is about $\left(15^{\circ} / 45^{\circ}\right)$. The plotting of the top salt bed with $\left(15^{\circ} / 45^{\circ}\right)$ on the vertical cross section (Figure 6) shows that the roof of the cavity is far enough that made the cavity is suitable to store LPG.

The comparison of geometric properties of the cavity derived from the 1989 and 2015 survey. Table 5 shows high variation in the geometric properties with high volume increase of the cavity due to the bad operation conditions that relate to pumping under saturated brine while unloading the cavity that causes leaching. Gas storage caverns were developed mainly for seasonal storage with one or few cycles per year Gas typically. Is injected in the summer and withdrawn in winter when demand is higher [7]. The operation records of this cavity refer to increase the numbers of injections and withdraw operations, these operations contribute to increase the leaching that cause high increase in the volume of the cavity (Table 6). 
Citation: Al-Sulaiman FA, Fadaws AH, Ahmed TA (2017) Geologic Evaluation of Kirkuk Underground Storage Project. J Pet Environ Biotechnol 8: 340. doi: 10.4172/2157-7463.1000340

Page 4 of 4

\section{Conclusion}

The geologic evaluation of Kirkuk underground storage cavities was conducted according to its shape, its relation to the top of salt bed, purity of salt as well as the tectonic setting of the area. The vertical cross section of the cavities shows that:

- Most cavities have irregular shape due to the presence of marls and silt as inclusions in the salt bed.

- The roof of the cavity no.2 shows longitudinal extension to south west direction, that made the roof is too near to the top of the salt bed, and the cavity can be used to store LPG after conducting tightness test.

- The vertical cross section of the cavity no. 5 show that the roof the cavity is about $2 \mathrm{~m}$ to top of salt bed that made the cavity is not safe to store LPG.

- The geometric properties of the cavities no.6 and no.7 show volume increase during last 25 years of operation due to bad operation conditions represented by increasing the numbers of filling and unloading operations (more than 5 times) for one year.

\section{References}

1. Dreyer W (1920) Underground storage of oil and gas in salt deposits and other non-hard rocks. Printed in Germany by Grammlich, Pliezhausen, Germany.

2. Buday T, Jassim SZ (2000) The regional geology of Iraq, Vol, Stratigraphy and paleogeography. Dar Al-Kutib Pub. House, Mosul, Iraq, 445p.

3. Dimitrov D, Mustafa M, Toma N (1983) Main industrial mineral deposits of lower FARS formation in Iraq, Geological Congress on middle east (GEOCOME), Baghdad.

4. North Oil Company (2010) Final well report of KGS-2, 5, 6, 7, 8, Qatar.

5. Jassim SZ, Goft JC (2006) Geology of Iraq, published by Dolin, Prague and Moravian Museum, Brno, Czech Republic. p. 354.

6. Sofra Gas Report (1984) Assessment of the leaching duration for obtaining a collective volume. Library of Petroleum Engineering Department. North Oi Company, Qatar.

7. Berest $P$ (2011) Thermo-mechanical aspect of high frequency cycling in salt storage caverns, International Gas Union Research Conference, Seoul, South Korea. 